\title{
Strontium 89 Combined with Gemcitabine in Androgen-Resistant Prostate Cancer: Results of a Phase I-II Study
}

\author{
Keizman Daniel, Maimon Natalie, Stefansky Irena, Sarid David, Levita Moshe, Vexler Akiva and \\ Ben-Yosef Rami*
}

Uro-Oncology Service, Division of Oncology, Tel-Aviv Sourasky Medical Center, Sackler Faculty of Medicine, Tel-Aviv University, Tel Aviv, Israel

\begin{abstract}
Background: Strontium 89 (Sr89), a beta-emitter particle that precipitates in bone, has a palliative role in the treatment of painful bony metastases in androgen-resistant prostate cancer (ARPC) patients. Questionable additional benefit has been reported when it was combined with chemotherapy.

Aim: To evaluate the efficacy of Sr89 given in combination with gemcitabine in ARPC patients with painful bony metastases.

Methods: Gemcitabine was given at a loading dose of $1000 \mathrm{mg} / \mathrm{m}^{2}$ on day 1 . A single dose of strontium-89 (4mCi) was administered on day 8. On day 29, gemcitabine at a dose of 100 (dose level 1), 200 (dose level 2) and 400 (dose level 3) $\mathrm{mg} / \mathrm{m}^{2}$ was delivered for once weekly for 7 weeks. The evaluated parameters included (a) PSA levels, (b) pain relief and change in ECOG performance status, and (c) bone scan findings.

Results: Nine patients were entered into this study. Four patients each completed dose levels 1 and 2. One patient received dose level 3. Seven (78\%) patients achieved an improvement in their bone scan findings (complete response in one patient, improvement in two, and stable disease in four) that led to pain relief and an improvement in quality of life. PSA decreased $(>50 \%)$ in four $(44 \%)$ patients and $<50 \%$ in one patient. Median survival was 19.4 months. One patient on dose level 3, who had coronary artery disease, developed chest pain that required hospitalization. No further therapy on dose level 3 was given. No grades 3 or 4 side effects occurred in patients on dose levels 1 or 2.

Conclusions: The combination of Sr89 and gemcitabine was well tolerated at the doses of $4 \mathrm{mCi}$ and $200 \mathrm{mg} / \mathrm{m}^{2}(\mathrm{dose}$ level 2), respectively. The treatment was associated with improvement in bone scan findings, improved quality of life and a decrease of PSA. Further studies investigating this regimen are warranted.
\end{abstract}

Key Words: Strontium-89, Low-dose gemcitabine, androgen-resistant prostate cancer, phase I-II study.

\section{INTRODUCTION}

The skeleton is the most common site of metastasis and tumor progression in prostate cancer. It responds initially to hormonal manipulation by androgen withdrawal and peripheral androgen blockade. However, the inevitable progression to an androgen-resistant disease leads to a decreased quality of life and shortens survival $[1,2]$.

The bone-targeting radioisotope strontium 89 ( $\mathrm{Sr} 89)$ is preferentially taken up by bone, at sites of high skeletal metabolic activity, such as osteoblastic skeletal metastases. It emits beta particles that lead to a palliative effect (pain relief and reduction in pathologic fractures) in androgen-resistant prostate cancer (ARPC) [1-3]. Enhancement of this palliative effect by combination with chemotherapy was reported in several phase II studies [4-6].

*Address correspondence to this author at the Department of Oncology, Tel Aviv Sourasky Medical Center, Affiliated with Tel-Aviv University School of Medicine, 6 Weizmann Street, Tel Aviv, Israel, 64239; Tel: +972-36974833; Fax: +972-3-6974832;

E-mail: ramiby@post.tau.ac.il, rby@tasmc.health.gov.il
Gemcitabine, an anti-metabolite agent with a low toxicity profile, was evaluated as a monotherapy or as a part of a combination regimen in ARPC [7-9]. It had a documented radio-enhancer potential in various cancers, such as pancreatic and head and neck tumors $[10,11]$.

The aim of the present study was to prospectively evaluate the efficacy of a full dose of $\mathrm{Sr} 89$ given in combination with low-dose gemcitabine $\left(100-400 \mathrm{mg} / \mathrm{m}^{2}\right.$ once weekly) in patients with ARPC and bony metastases.

\section{PATIENTS AND METHODS}

\section{Patients}

ARPC patients who had painful skeletal metastases that had been documented on a recent bone scan were eligible to participate in this study. All patients had an ECOG performance status of $0-2$ and an expected survival of at least 3 months. Due to a potential hematological suppression as a side effect of both Sr89 and gemcitabine, patients with compromised bone marrow were excluded. 
Table 1. Patients' Characteristics

\begin{tabular}{|c|c|c|c|c|c|c|c|c|c|}
\hline & \multicolumn{4}{|c|}{ Dose Level 1 } & \multicolumn{3}{c|}{ Dose Level 2 } & Dose Level 3 \\
\hline \hline No. & 1 & 2 & 3 & 4 & 5 & 6 & 7 & 8 & 9 \\
\hline Age in years & 60 & 57 & 59 & 69 & 81 & 85 & 80 & 80 & 78 \\
\hline PSA level (ng/ml) & 821 & 1449 & 5.3 & 211 & 347 & 7.6 & 115 & 106 & 18 \\
\hline Pain score & 5 & 6 & 5 & 6 & 7 & 5 & 0 & 6 & 0 \\
\hline ECOG status & 1 & 2 & 2 & 2 & 2 & 2 & 0 & 2 & 0 \\
\hline
\end{tabular}

\section{Study Design}

The planned dose of gemcitabine was a 12-week cycle in which a loading dose of $1000 \mathrm{mg} / \mathrm{m}^{2}$ would be given on day 1 , followed by 100 (dose level 1), 200 (dose level 2) or 400 (dose level 3) $\mathrm{mg} / \mathrm{m}^{2}$ on day 29 and then once weekly for 7 weeks. A single dose of $\mathrm{Sr} 89$ (4mCi) was administered on day 8. A three week period between Sr89 and gemcitabine was chosen to decrease possible medical staff exposure (such as during the drawing of blood samples) [12], based on the local ethical committee's recommendations.

\section{Definition of Response}

Treatment response was evaluated by (a) reduction of PSA levels, (b) pain relief and change in ECOG performance status and (c) bone scan findings. The PSA level was measured weekly. According to an NCI consensus conference [13], a partial response was defined as a decline $\geq 50 \%$ that persisted for at least 8 weeks, a progressive disease as an increase of $\geq 25$ compared with the baseline level, or an absolute increase of $\geq 10 \mathrm{ng} / \mathrm{mL}$ that persisted for at least 2 weeks. Patients who did not fulfill the criteria for progression or response within 8 weeks were considered to have stable disease. Pain relief was assessed weekly by a numerical rating scale from $0=$ no pain to $10=$ worst possible pain [14]. ECOG performance status was assessed weekly. A bone scan was performed before treatment and at treatment cessation. The appearance of any unequivocal new lesions was considered as progressive disease. Toxic effects were graded according to the National Cancer Institute Common Terminology Criteria for Adverse Events, Version 3 [15]. Complete blood counts were obtained before each gemcitabine administration. Survival duration was measured from study entry until death. The study was approved by The Tel Aviv Medical Center Institutional Review Board, and informed consent was obtained from all participants.

\section{RESULTS}

\section{Patients}

Nine patients, aged 57-85 years (mean 72), were enrolled into this study. All patients suffered from prostate cancer and painful bony metastases, confirmed by whole body scan. The ECOG performance status was 2 in six patients, 0 in two patients, and 1 in one patient. None received prior radiotherapy to the skeleton or underwent any chemotherapy. Four patients were treated at dose level 1 , and four patients at dose level 2. One patient was planned to receive dose level 3 but developed chest pain that required hospitalization during the fourth week of treatment. He had documented ischemic heart disease and was now diagnosed with acute coronary syndrome. Gemcitabine (day 28) was not given as planned and the treatment was stopped. No further patients were enrolled to dose level 3. Patients characteristics are presented in Table $\mathbf{1}$.

\section{PSA Decrease}

- 44\% (4/9) patients ( 3 patients at dose level 1 and one patient at dose level 2) had a PSA decrease $>50 \%$. The mean onset time of PSA decline was 2.75 months (range 2-4) from the beginning of treatment, and the mean duration of response was 8.5 (range 4-12) months. 44\% (4/9) patients experienced progressive disease and one patient (at dose level 2) had stable PSA level disease (Table 2).

\section{Pain Relief}

- 78\% (7/9) patients achieved pain relief. The mean pretreatment pain score of 6 (range 5-7) decreased to a mean score of 2 (range 1-3). Pain relief was achieved after a mean of 2.14 months (range 1-5), and lasted for a mean of 7.6 months (range 3-12). This decrease in pain intensity was accompanied by a $50 \%$ reduction in the total daily dose of required analgesics (Table $\mathbf{2}$ ).

\section{ECOG Performance Status}

78\% (7/9) patients reported an improved in functional capacity and improvements in overall quality of life. These patients had a mean pre-treatment ECOG performance status score of 1.7 (range 1-2), and it decreased to a mean score of 0.7 (range 0-1). Their time pattern (onset, duration) of improvement was similar to that described for pain relief. One patient had a pre-treatment ECOG performance status score of 0 that had lasted for one year, and another patient (11\%) had no improvement whatsoever in his performance statusl (Table 2).

\section{Bone Scan Findings}

$78 \%$ (7/9) patients had a bone scan response: four patients had a stable finding, two patients had an improvement and one patient had a complete response. The onset of bone scan improvement in the three patients was noted after a mean duration of 4.6 months ( 2,5 , and 7 months) from the beginning of treatment, and lasted for 11.25 months (range 7-18 months). Two patients underwent a worsening of their bone scan (Table 2 ). 


\section{Overall Survival}

Median overall survival for all nine patients was 19.4 months (range 7-34). Based on PSA response, the overall survival was 20,22 , and 18.25 months in those who had partial, stable and progressive disease, respectively. The overall survival was $32,25,20.5,5.5$ months for the patients who had complete, improved, stable or progressive response on bone scan findings, respectively (Table $\mathbf{2}$ ).

\section{Treatment Related Toxicity}

There were no severe (grade 3 or 4) side effects on dose level 1 or 2 . Three patients had grade 2 thrombocytopenia (two patients at level 1 and one at level 2), two had grade 1 anemia, two others had non-specific mild weakness and one had a mild drug eruption. The only patient at dose level 3 developed chest pain before receiving the 28th gemcitabine dose. This serious adverse effect was not neceseralily related to the treatment medication (the patient had a known heart disease and was on cardiac medication) however, it precluded our enrollment of additional patients to this dose level (Table 2).

\section{DISCUSSION}

The skeleton is the most common site of metastasis and tumor progression in ARPC. This finding presents an opportunity for bone-seeking targeted therapy, such as Sr89, a beta-emitting radionuclide that selectively localizes in bone mineral at sites of active osteogenesis [16]. Sr89 has a palliative effect in ARPC patients [1-3], however, it does not improve the overall survival whether it is given alone or in combination with other chemotherapeutic agents such as doxorubicin $[6,17]$ or cisplatin $[5,18]$. In a phase II randomized study, Tu et al. [6] reported that Sr89 given in combination with doxorubicin as a consolidation treatment (following 2 cycles of induction regimen consisting of ketoconazole, doxorubicin, estramustine and vinblastine) improved the survival of a subgroup of patients. Those authors suggested that the clinical benefit from bone-targeted therapy in patients with ARPC may extend beyond PSA decline and pain control. Recently, a similar study using doxorubicin, ketoconazole, paclitaxel and estramustine combined with Sr89 (given as an induction regimen) was found as effective in prolongation of overall survival with acceptable toxicity [19].

In the current study, we evaluated the combination of gemcitabine and Sr89. We preferred the use of gemcitabine due to its radio-enhancing effect [20] and its possible activity in patients with metastatic prostate cancer [7-9]. We were aware of the possible side effect of bone marrow depression that might be intensified with the combination of Sr89. This reason, among others, led us to use a lower dose of gemcitabine (starting level of $100 \mathrm{mg} / \mathrm{m}^{2}$ ) as the first drug level, and, indeed, our results demonstrated that the combination of Sr- 89 and low dose gemcitabine $\left(100 / 200 \mathrm{mg} / \mathrm{m}^{2}\right)$ was safe. The toxic effects were primarily mild thrombocytopenia and anemia, without neutropenia. This bone marrow toxicity profile does not differ from the one observed with $\mathrm{Sr}-89$ alone. There was only one incidence of dose limiting toxicity due to a grade 2 thrombocytopenia and it was reversible. In terms of anti-tumor effect (i.e., PSA response, pain relief, performance status improvement, bone scan improvement),

Table 2. Treatment Response and Toxicity

\begin{tabular}{|c|c|c|c|c|c|c|c|c|c|}
\hline \multirow[b]{2}{*}{ Patient No. } & \multicolumn{4}{|c|}{ Dose Level 1} & \multicolumn{4}{|c|}{ Dose Level 2} & \multirow{2}{*}{$\begin{array}{c}\text { Dose Level 3 } \\
9\end{array}$} \\
\hline & 1 & 2 & 3 & 4 & 5 & 6 & 7 & 8 & \\
\hline PSA decrease & 396 & 88 & 19.7 & 0.49 & 282 & 11.9 & 165 & 46 & 47 \\
\hline Response & PR & PR & $\mathrm{PD}$ & PR & SD & $\mathrm{PD}$ & PD & PR & PD \\
\hline $\begin{array}{l}\text { PSA Response duration } \\
\text { in months }\end{array}$ & 4 & 6 & 0 & 12 & 3 & 0 & 0 & 12 & 0 \\
\hline Min pain & 1 & 2 & 3 & 1 & 3 & 2 & 0 & 2 & 0 \\
\hline $\begin{array}{l}\text { Time to pain progression } \\
\text { in months }\end{array}$ & 6 & 6 & 7 & 7 & 3 & 12 & 12 & 12 & 0 \\
\hline Min ECOG & 0 & 1 & 1 & 0 & 1 & 1 & 0 & 1 & 0 \\
\hline ECOG TTP in months & 6 & 6 & 7 & 12 & 3 & 12 & 12 & 12 & 0 \\
\hline Bone scan reaction & $\mathrm{SD}$ & PR & PR & $\mathrm{CR}$ & SD & PD & $\mathrm{SD}$ & $\mathrm{SD}$ & N.A. \\
\hline Side effect (toxicity level) & $\operatorname{PLT}(2)$ & & $\mathrm{W}(1)$ & $\begin{array}{c}\mathrm{Hb}(1) \operatorname{PLT}(2) \\
\mathrm{W}(1)\end{array}$ & $\begin{array}{c}\operatorname{PLT}(2) \mathrm{W}(1) \\
\mathrm{Hb}(1)\end{array}$ & & & $\mathrm{S}(1)$ & Chest pain \\
\hline Overall survival in months & 12 & 16 & 34 & 32 & 22 & 14 & 28 & 20 & 7 \\
\hline
\end{tabular}

CR-Complete Response, PR-Partial Response, SD-Stable Disease, PD-Progressive Disease, N.A.-Not Available, PLT-Platelets, W-Weakness Hb-Hemoglobin, S-Skin. 
our findings demonstrated a clinical benefit that probably would not be observed with either drug alone $[7,16]$. The present study was originally designed to include more patients in dose level 3, however, it was stopped earlier because one patient suffered chest pain. Even though this patient had prior ischemic heart disease, we cannot exclude this symptom as having been initiated by the treatment regimen. A similar study on the combination of $\operatorname{Sr} 89(55 \mu \mathrm{Ci} / \mathrm{kg}$, day 8$)$ and high-dose gemcitabine $\left(600 \mathrm{mg} / \mathrm{m}^{2}\right.$ or $800 \mathrm{mg} / \mathrm{m}^{2}$ days $1,8,15,43,50,57)$ was reported by Pagliaro et al. [21]. The maximal tolerated dose used in their study was 800 $\mathrm{mg} / \mathrm{m}^{2}$ and no response was observed. They concluded that further studies at this dose level and schedule were not warranted. Our results with a lower dose of gemcitabine are contrary to their conclusions. The difference can partially be explained by prior exposure to chemotherapy: 13 of their 15 patients were exposed to prior chemotherapy compared to none of our patients whatsoever.

Docetaxel $(75 \mathrm{mg} / \mathrm{m} 2$ every three weeks) plus daily prednisone (5 mg twice a day) has now become the recommended first-line treatment for ARPC [22, 23]. Nevertheless, alternative and possibly more effective first-line treatments, especially in patients that are unable to tolerate docetaxel, are needed. The outcome in the current study in terms of response rate (44\%), time to disease progression (8.5 months), mean overall survival (19.4 months), and treatment-associated toxicity (no grade $3 / 4$ adverse reactions) were at least as good as those achieved in the Taxotere study. In addition, it is not clear what should be the secondline treatment after the initial taxane-based therapy. Optional treatments include combinations of mitoxantrone-prednisone, estramustine phosphate-paclitaxel-etoposide and vinorelbine based regimens. These regimens are modestly effective in terms of response rate $(20 \%-40 \%)$, time to progression (3-4 months) and median survival (10-14 months), and they are all associated with significant toxicity [24-27]. Other alternatives, such as bone-seeker radioactive medications (alpha or beta emitters), combined with chemotherapy might be indicated.

In summary, Sr89 combined with low-dose gemcitabine is relatively well tolerated and associated with improvements in quality of life, PSA decline and no progression in bone scan findings. Future prospective studies on the use of bone-seeker medications combined with chemotherapy are warranted.

\section{REFERENCES}

[1] James ND, Bloomfield D, Luscombe C. The changing pattern of management for hormone-refractory, metastatic prostate cancer. Prostate Cancer Prostatic Dis 2006; 9: 221-9.

[2] Berthold DR, Sternberg CN, Tannock IF. Management of advanced prostate cancer after first-line chemotherapy. J Clin Oncol 2005; 23:8247-52.

[3] Friedlans J. Local and systemic radiation for palliation of metastatic disease. Urol Clin North Am 1999; 26: 391-402.

[4] Akerley W, Butera J, Wehbe T, et al. A multiinstitutional concurrent chemoradiation trial of strontium-89, estramustine, and vinblastine for hormone refractory prostate carcinoma involving bone. Cancer 2002; 94:1654-60.

[5] Sciuto R, Festa A, Rea S, et al. Effects of low-dose cisplatin on Sr89 therapy for painful bone metastases from prostate cancer: a randomized clinical trial. J Nucl Med 2002; 43: 87-8.
[6] Tu SM, Millikan RE, Mengistu B, et al. Bone-targeted therapy for advanced androgen-independent carcinoma of the prostate: a randomized phase II trial. Lancet 2001; 357: 336-41.

[7] Morant R, Bernhard J, Maibach R, et al. Response and palliation in a phase II trial of gemcitabine in hormone-refractory metastatic prostatic carcinoma. Ann Oncol 2000; 11: 183-8.

[8] Vogelzang NJ. Future directions for gemcitabine in the treatment of genitourinary cancer. Semin Oncol 2002; 1: 40-5.

[9] Di Lorenzo G, Autorino R, Giuliano M, et al. Phase II trial of gemcitabine, prednisone, and zoledronic acid in pretreated patients with hormone refractory prostate cancer. Urology 2007; 69: 34751 .

[10] Blackstock AW, Bernard SA, Richards F, et al. Phase I trial of twice-weekly gemcitabine and concurrent radiation in patients with advanced pancreatic cancer. J Clin Oncol 1999; 17: 2208-12.

[11] Eisbruch A, Shewach DS, Bradford CR, et al. Radiation concurrent with gemcitabine for locally advanced head and neck cancer: a phase I trial and intracellular drug incorporation study. J Clin Oncol 2001; 19: 792-9

[12] Ben-Yosef R, Pelled O, Marko R, et al. Establishing schedules for repeated doses of strontium and for concurrent chemotherapy in hormone-resistant patients with prostate cancer: measurement of blood and urine strontium levels. Am J Clin Oncol; 28: 138-42.

[13] Bubley GJ, Carducci M, Dahut W, et al. Eligibility and response guidelines for Phase II clinical trials in androgen-independent prostate cancer: recommendations from the Prostate-Specific Antigen Working Group. J Clin Oncol 1999; 17: 3461-7.

[14] Jensen MP, Karoly P, Braver S. The measurement of clinical pain intensity: a comparison of six methods. Pain 1986; 27: 117-26.

[15] National Cancer Institute Common Terminology Criteria for Adverse Events v3.0 Web site. Available from: http://ctep. cancer.gov/forms/CTCAEv3.pdf file:///E:/cgi-bin/reflink? object=TYPE\%3DJCIT\%26BIBID\%3D6\%26SNM\%3DTannock\% 26FNM\%3DIF\%26SNM\%3DOsoba\%26FNM\%3DD\%26SNM\% 3DStockler\%26FNM\%3DMR\%26ATL\%3DChemotherapy with mitoxantrone plus prednisone or prednisone alone for symptomatic hormone-resistant prostate cancer\%3A a Canadian randomized trial with palliative end points\%26JTL\%3DJ Clin Oncol.\%26PYR\% 3D1996\%26VID\%3D14\%26PPF\%3D1756\%26PPL\%3D1764\%26 ADOI\%3D10.1002/cncr.11412\%26EVIEW\%3DY\%26ENABLEIS I\%3DN\%26ENABLECAS\%3DY\%26EN

[16] Robinson RG, Blake GM, Preston DF, et al. Strontium-89: treatment results and kinetics in patients with painful metastatic prostate and breast cancer in bone. Radiographics 1989; 9: 271-81.

[17] Tu SM, Delpassand ES, Jones D, Amato RJ, Ellerhorst J, Logothetis CJ. Strontium-89 combined with doxorubicin in the treatment of patients with androgen-independent prostate cancer. Urol Oncol 1996; 2: 191-7.

[18] Mertens WC, Porter AT, Reid RH, Powe JE. Strontium-89 and low-dose infusion cisplatin for patients with hormone refractory prostate carcinoma metastatic to bone: a preliminary report. J Nucl Med 1992; 33: 1437-43.

[19] Amato RJ, Hernandez-McClain J, Henary H. Bone-targeted therapy: phase II study of strontium- 89 in combination with alternating weekly chemohormonal therapies for patients with advanced androgen-independent prostate cancer. Am J Clin Oncol 2008; 31: 532-8.

[20] Pauwels B, Korst AE, Andriessen V, et al. Unraveling the mechanism of radiosensitization by gemcitabine: the role of TP53. Radiat Res 2005; 164: 642-50.

[21] Pagliaro LC, Delpassand ES, Williams D, Millikan RE, Tu SM, Logothetis CJ. A Phase I/II study of strontium- 89 combined with gemcitabine in the treatment of patients with androgen independent prostate carcinoma and bone metastases. Cancer 2003; 97: 298894.

[22] Tannock IF, de Wit R, Berry WR, et al. Docetaxel plus prednisone or mitoxantrone plus prednisone for advanced prostate cancer. N Engl J Med 2004; 351:1502-12.

[23] Basch EM, Somerfield MR, Beer TM, et al. American Society of Clinical Oncology endorsement of the Cancer Care Ontario Practice Guideline on nonhormonal therapy for men with metastatic hormone-refractory (castration-resistant) prostate cancer. Clin Oncol 2007; 25: 5313-8.

[24] Rosenberg JE, Weinberg VK, Kelly WK, et al. Activity of secondline chemotherapy in docetaxel-refractory hormone-refractory 
prostate cancer patients: randomized phase 2 study of ixabepilone or mitoxantrone and prednisone. Cancer 2007; 110: 556-63.

[25] Meluch AA, Greco FA, Morrissey LH, et al. weekly paclitaxel, estramustine phosphate, and oral etoposide in the treatment of hormone-refractory prostate carcinoma: results of a Minnie Pearl Cancer Research Network phase II trial. Cancer 2003; 98: 2192-98.
[26] Borden LS Jr, Clark PE, Lovato J, et al. Vinorelbine, doxorubicin, and prednisone in androgen-independent prostate cancer. Cancer 2006; 107: 1093-100.

[27] Caristi N, Maisano R, Iorfida M, et al. Oral vinorelbine as first line chemotherapy in unfit elderly patients with hormone-refractory prostate cancer. J Chemother 2008; 20: 368-73.

(C). Keizman et al.; Licensee Bentham Open.

This is an open access article licensed under the terms of the Creative Commons Attribution Non-Commercial License (http://creativecommons.org/licenses/ by-nc/3.0/) which permits unrestricted, non-commercial use, distribution and reproduction in any medium, provided the work is properly cited. 